\title{
Tools for Online Collaboration: Do they contribute to Improve Teamwork?
}

\author{
Inês Lopes
}

Instituto Universitário de Lisboa (ISCTE-IUL).Graphic Designer, and Researcher in Information and Communication Technologies, Lisboa, Portugal Email: iaqls@iscte-iul.pt

\begin{abstract}
Abílio Oliveira
Instituto Universitário de Lisboa (ISCTE-IUL), and Information Sciences, Technologies and Archictecture Research Centre (ISTAR-IUL), Lisboa, Portugal Email: abilio.oliveira@iscte.pt

Carlos J. Costa

Instituto Universitário de Lisboa (ISCTE-IUL), and Information Sciences, Technologies and Archictecture Research Centre (ISTAR-IUL), Lisboa, Portugal Email: carlos.costa@iscte.pt
\end{abstract}

\section{Doi:10.5901/mjss.2015.v6n6s4p511}

\section{Abstract}

In the last decades, the fast growth of Information and Communication Technologies changed our way to communicate and share information. Traditional groups or teams frequently give way to virtual teams, working with tools for online collaboration. Interaction between persons geographically dispersed has become easier. However, the use of new collaboration tools can also bring many challenges. Some technologies, like e-mail, can create delays on reply or even misunderstandings, case the message is not well understood by the recipient. Can these new technologies improve the productivity and enhance the creativity between group members, improving also their confidence and motivation? Although virtual teams have a high capacity to adapt to constant market changes, personal interactions are still important, mainly to clarify tasks and goals. The main purpose of this study is to understand how tools for online collaboration may improve the productivity (and enhance creativity) in teamwork. This study was conducted through an internet platform and the survey was hosted online by SurveyMonkey.com. We intended to verify, among other questions, what users think about different collaboration tools, how often they use these tools, and how they perceive these technologies as adequate ways to communicate, to work with, and to improve productivity. Findings show that e-mail is the most used tool, and personal contact is still more important for teamwork than any tools for online collaboration. Our results contribute to perceive in what extent collaboration tools are indeed an asset or a barrier in teamwork.

Keywords: Collaboration tools, traditional teams, virtual teams, productivity, creativity, communication, confidence, motivation.

\section{Introduction}

Currently with the existing tools for collaboration online, we may create teams composed by persons with different skills and knowledges, having the possibility to storage and share information easily. Working online shortened the distance among people and organizations. These teams also have a greater adaptability to market changes. We may find diversified collaboration tools to promote teamwork and, generally, these tools provide some good challenges - e-mail is just an example of an asynchronous tool that we use daily. But even this simple tool may fail.

In a collaboration context, the e-mail server or service can cause delays or misunderstandings that influence team performance negatively. The relationships in virtual teams depend on a successful sharing of information, as well as on a regular and effective communication.

The highly demanding market, and the need to reply to very high levels of competition, in order to reach (or approach to) the level of other European countries, it was one of the starting points to develop this study. The team's success depends on good communication among members. Otherwise the consequences may be irreversible (e.g. meeting deadlines, lack of trust in the final outcome of the work). Productivity and creativity are two important features to 
encourage our economy, weakened by the present financial crisis.

Nowadays organizations and teams need to be effective to discuss and find solutions, in order to solve problems faster. The flexible and creative teams are the key to respond to competitive market. But can tools for online work and communication improve teamwork?

The research's main purpose is to perceive if tools for online collaboration may improve productivity and promote creativity in teamwork. We intended to verify, among other questions, what users think about different collaboration tools, how often they use these tools, and how they perceive these technologies as adequate ways to communicate, to work with, and to improve productivity. We hope our results contribute to perceive in what extent collaboration tools are indeed an asset or a barrier in teamwork.

\subsection{Virtual teams}

Nowadays collaboration doesn't know boundaries. Contemporary work is characterized by getting together workers with several knowledges, anywhere in the world. So, virtual teams may be generally defined as a group of members culturally and organizationally different, who are: grouped temporary; physically dispersed; linked by weak bonds; and focused on performing one or more non-routine tasks (Wong \& Burton, 2000).

The interaction through use of technologies is more impersonal, more oriented to task, more professional and less friendly than face-to-face interaction (e.g. Schmidt et al., 2001). Therefore, an effective communication is important, mainly in the first stages of team development, to sustain trust (Anderson et al., 2007, p. 2656). However, working with dispersed members may result in long delays along the work development process (Herbsleb \& Mockus, 2003). Additionally, members who acquired large information sharing, reveal high levels of performance (Cummings, 2004).

Dispersed members, when faced with a problem, usually contact with local colleagues, because members distributed locally and temporally may lose some communication capabilities, common in face-to-face interaction, such as gestures, observation, facial expressions and visual contact (Driskell, Radtke \& Salas, 2003). Other researchers identified six challenges in virtual teams: distance, time, technology, culture, trust and leadership. According to Cascio (2000), there are five disadvantages in a virtual team: lack of social interaction, loss of synergies and the characteristics of face-to-face interaction, lack of confidence and great concern about predictability and security. Traditional teams tend to have more satisfation, more support, and to provide innovative solutions, due to their constructive style. The passive and aggressive style in virtual teams may create conflicts and less satisfaction, resulting in a worse decision making. In this sense, sucessful virtual teams are those which promote collaboration, confidence and cohesion among members (Gera, 2013).

\subsection{Collaboration tools}

According to Bolstad \& Endsley (2003) there are four typical characteristics of collaboration: (1) time of collaboration (real time or not); (2) collaboration predictability - collaboration occurs in previously scheduled times or marking provided; (3) place of collaboration - collaboration can both happen to individuals co-located or distributed; and finally (4) level of interaction. Teamwork in distributed teams may include face-to-face interaction (having formal and informal discussions), telephone (e.g. audioconference, voice mail, telephone conversations) and communication technologies (e.g. e-mail, electronic discussions, chat, and others). Communication technologies are structures which provide resource sharing knowledge (intranet or groupware). However, face-to-face meetings are still essential for the effective performance (Watson-Manheim \& Belanger, 2002).

Face-to-face interaction is definitely the most used way to create a perfect collaboration environment. Nevertheless, there are countless tools which also may promote team collaboration (e.g. the videoconference, as promoted by Skype, GoToMeeting, etc.). Obviously this involves the use of a computer network where two or more participants, dispersed in different locations, transmit audio and video data (image and text) through a computer in a conference format. The conference call (e.g. Skype, ZOHO Meeting) also known as teleconferencing, allows the meeting between two or more participants connected via a network (internet or intranet), dial-up or satellite, in real time, in which communication can be made by voice or fax. Instant Messages or chat (e.g. Hangout, Lync Online) is a universal collaboration tool, versatile and accessible - it provides a synchronous communication text between two or more users through computers. Although social networks, such as facebook and twitter, are not considered as collaboration tools, they create an environment that encourages people to link to each other, sharing different type of contents and information, in real-time. Social networks are indeed applications frequently used by users for long time periods, and have a great potential to become a collaboration tool, allowing the creation of information sharing spaces (Lomas, Burke \& Page, 2008). 
E-mail is the simplest form of asynchronous communication, allows the composition of a message by a given person, which is sent to one or more recipients connected through a computer. This is the most used tool in organizations, allows easy storage, recovery and editing (Godar \& Ferris, 2004). However, this tool doesn't provide immediate feedback which may bring conflicts, due low levels of knowledge sharing between members, as well as difficulty to build confidence and understand the context and relevance of information (Friedman \& Currall, 2003; Jarvenpaa \& Leidner, 1998).

Project management tools (e.g. Microsoft Project, Projectlibre) include tasks, milestones, time sheets and Gantt charts. These tools allow users update work status by percentage completed (Xu, Zhang, Harvey \& Young, 2008).

Tools to share documents (e.g. Google Drive, Huddle, Microsoft Web Apps) also have great potential to promote collaboration, allowing, for instance, editing documents in real time and may promoting brainstorming and collective articulation of ideas (Lomas, Burke \& Page, 2008). Other tools to share files (e.g. Dropbox, WeTranfer) and presentations (e.g. Slideshare, Prezi) may also be very useful to collaborative work.

Content Management System (CMS) (e.g. Drupal, Joomla) enable to exchange information and manage contents; it may be adapted to specific groups which want to share important information within teamwork. Last, blogs (e.g. Wordpress, Blogger) enable to comment and discuss ideas, or simply to communicate internally in a group, organizing automatically the content in chronological order.

\subsection{Productivity and creativity in virtual teams}

There are four main areas where virtual world has impact in teamwork: communication, confidence, team's participation and coordination, as long as work shows good results. Virtual teams face several challenges related with communication. These may cause conflicts, errors or hamper team's formation and task completion (Cramton, 2001).

High productivity levels are associated with easy communication patterns, continuous and improvised interaction of co-located teams (Olson et al., 2002).

Tasks performed by teams should be fixed and sequenced in order to achieve proposed goals. For Hogan \& Salas (1981) group tasks are classified in six categories: (1) mechanical or technical tasks - require the construction and operation of things; (2) intellectual and analytical tasks - require the generation of ideas and problem solving; (3) aesthetic tasks or imaginative - require creativity or artistic endeavor; (4) social tasks - require training, support or assisting others; (5) manipulation and persuasion tasks - require motivation or other's persuasion; and (6) logic tasks or precision - require the performance of routine tasks, detailed or standardized. In a cohesive group, members reveal higher levels of satisfaction (Back, 1951; Lott \& Lott, 1961; Curtis \& Miller, 1986). However, technologies may reduce the intimacy among members and complicate the relationships, thus decreasing the cohesion (Warkentin et al., 1997).

In a business environment, be original is not enough, be creative implies have an useful and actionable idea. Creativity influences an organization in improvement of a product or in a new way to approach a work process. Personal flexibility and creativity to approach a problem is a characteristic of each one's creative ability. Experience and motivation are both important. Experience includes all knowledges, technical skills and basic talent to think; in otther words, it is what a person uses in a wide area of their work (Amabile, 1998). According to Amabile (1998), there are two types of motivation: extrinsic and intrinsic - extrinsic motivation comes from something external, such as a reward, and intrinsic motivation is related with personal interest, satisfaction and challenge that work provides to each one (Amabile, 1998).

Creativity may help virtual teams to become more effective. Many researchers think that the key for success is developing intellectual features, and acquiring a set of thoughts and abilities, such as creativity (e.g. Roffe, 1999). There are numerous definitions assigned to creativity. However Firestien (1996) reported Mel Rhodes (1981), in the search for a universal definition, describing creativity following four related terms: person, process, product and press.

A creative person is someone highly active in mind, characterized by various cognitive factors: fluency, flexibility, originality and elaboration; a creative process - when a certain problem is overcome by a creative thinking approach; creative press - involves creating an environment conducive to creativity; and, finally, creative product - corresponds to the result of creative work and may be associated with a product such as a specific behavior (Richards, 1999). This is a current meaning of creativity.

The team's performance may be influenced by their structural characteristics, related to the allocation of tasks, responsibilities and authority (Stewart \& Barrick, 2000). Nemiro (2001) identified several important aspects that influences creativity in virtual teams and results in high levels of performance: (1) clarify objectives - clear goals and objectives may help a team to be focused on their tasks, maintain harmony among members, and avoid false assumptions and indecisions, reducing conflict outbreaks; (2) trust among members; (3) communication patterns, to maintain a team connected, to create bonds and synergies among members; (4) know how to deal with creative barriers, such as rules 
and tradition (i.e., rank, formal barriers and procedural barriers), cultural barriers and resource barriers (lack of people, money, time, supplies and information necessary for creative thinking or to implement creative ideas) (Godar \& Ferris, 2004).

\section{Main Objective}

The main objective of this study is verify how often users use collaboration tools and how they perceive these technologies as adequate ways to communicate, to work with, to improve productivity and enhance creativity.

\section{Method}

This study involved 105 participants $(\mathrm{N}=105)$, women and men, between eighteen and sixty one years old. Data were collected through an internet platform and the survey was hosted online by SurveyMonkey.com.

Some of the questions under discussion were the following:

1. How often do you use the following tools*? (1- Never; to 5-Very Often)

2. How often do you use the following tools* in teamwork? (1- Never; to 5-Very Often)

3. In what extent do you identify with each of these ${ }^{\star \star}$ issues? (1- Totally Disagree; 2- Disagree;

3- Neither Agree nor Disagree; 4- Agree; 5- Totally Agree)

4. To what extent each of the following tools* are important to promote the communication between the members of a group? (1- Nothing; to 5- Very Much)

- Videoconference (ex: Skype, GoToMeeting); Audioconference (ex: Skype, ZOHO Meeting); Telephone Contact; Personal Contact (Face-to-Face); E-mail; File Sharing Applications (ex: Dropbox, WeTransfer); Shared Presentations (ex: Slideshare, Prezi); Instant Messages (ex: Hangout, Lync Online); CMS (ex: Joomla, Drupal); Social Networks (ex: Facebook, Twitter); Blogs (ex: Wordpress, Blogger); Shared Documents (ex: Google Drive, Microsoft Web Apps); Project Management (ex: Microsoft Project, Projectlibre)

- The virtual media facilitate the resolution of a problem.

Working online helps me feel motivated.

It is more viable achieve the proposed goals when we work in virtual environments.

Virtual environments provide me more confidence to do a work.

I believe that virtual tools help to develop a work in group.

I like to work with virtual tools.

Working in virtual team promotes creativity.

It is important to have regular communication.

I like that my team has good ideas.

Communication among members should be effective.

Team members should encourage each other.

The discussion of ideas is important.

There shouldn't be delays in replies to emails.

I feel free to express my opinion.

I usually work in team.

I trust more in my abilities.

A team must complete the work within the deadline.

A team must solve their problems.

I prefer to work face-to-face with my colleagues than in a virtual context.

Usually I feel motivated when I am performing a task.

\section{Main Results}

We observed that the most used tool in an individual work is the e-mail (cf. Table 1) and in teamwork the personal contact (face-to-face) is still important (cf. Table 2). Addicionally, in individual work participants also use frequently personal and telephone contact, as well as social networks.

On the other hand, in teamwork, the e-mail and telephone contact are also frequently used. 
Table 1 - Use of collaboration tools in individual work

\begin{tabular}{|l|c|c|c|}
\hline 1. How often do you use the following tools? & Average & Standard Deviation & N \\
\hline Videoconference (ex: Skype, GoToMeeting) & 2,68 & 1,497 & 105 \\
\hline Audioconference (ex: Skype, ZOHO Meeting) & 2,47 & 1,448 & 105 \\
\hline Telephone Contact & 4,55 & 0,796 & 105 \\
\hline Personal Contact (Cara-a-Cara) & 4,55 & 0,679 & 105 \\
\hline E-mail & 4,67 & 0,703 & 105 \\
\hline File Sharing Applications (ex: Dropbox, WeTransfer) & 3,39 & 1,376 & 105 \\
\hline Shared Presentations (ex: Slideshare, Prezi) & 2,21 & 1,246 & 105 \\
\hline Instant Messages (ex: Hangout, Lync Online) & 2,66 & 1,610 & 105 \\
\hline CMS (ex: Joomla, Drupal) & 1,60 & 1,165 & 105 \\
\hline Social Networks (ex: Facebook, Twitter) & 3,83 & 1,411 & 105 \\
\hline Blogs (ex: Wordpress, Blogger) & 2,22 & 1,387 & 105 \\
\hline Shared Documents (ex: Google Drive, Microsoft Web Apps) & 2,98 & 1,352 & 105 \\
\hline Management Projects (ex: Microsoft Project, Projectlibre) & 1,53 & 0,981 & 105 \\
\hline
\end{tabular}

In question three (cf. Table 3) we focused in productivity, creativity, confidence and motivation. For participants is important a team comply with deadlines and collaborate mutually, to achieve the proposed goals. Loss of cohesion and delays in replies on emails must be avoided $(A v g=4,50)$. Participants also agree that teamwork allow to achieve goals $(A v g=4,74)$. They prefer teamwork, but they also express that it is important the encouragement among team members, thus showing that cohesion and having a strong relationship are essential. The cohesion is related with motivation increase, better decision making and open communication (Budman et al., 1993).

Table 2 - Use of collaboration tools in teamwork

\begin{tabular}{|l|c|c|c|}
\hline 2. How often do you use the following tools in teamwork? & Average & Standard Deviation & N \\
\hline Videoconference (ex: Skype, GoToMeeting) & 2,34 & 1,440 & 105 \\
\hline Audioconference (ex: Skype, ZOHO Meeting) & 2,19 & 1,373 & 105 \\
\hline Telephone Contact & 4,28 & 1,024 & 105 \\
\hline Personal Contact (Cara-a-Cara) & 4,66 & 0,677 & 105 \\
\hline E-mail & 4,64 & 0,774 & 105 \\
\hline File Sharing Applications (ex: Dropbox, WeTransfer) & 3,34 & 1,505 & 105 \\
\hline Shared Presentations (ex: Slideshare, Prezi) & 2,24 & 1,376 & 105 \\
\hline Instant Messages (ex: Hangout, Lync Online) & 2,36 & 1,545 & 105 \\
\hline CMS (ex: Joomla, Drupal) & 1,47 & 1,010 & 105 \\
\hline Social Networks (ex: Facebook, Twitter) & 2,96 & 1,664 & 105 \\
\hline Blogs (ex: Wordpress, Blogger) & 1,68 & 1,079 & 105 \\
\hline Shared Documents (ex: Google Drive, Microsoft Web Apps) & 2,72 & 1,477 & 105 \\
\hline Management Projects (ex: Microsoft Project, Projectlibre) & 1,55 & 1,065 & 105 \\
\hline
\end{tabular}

Table 3 - Productivity, Creativity, Confidence and Motivation in virtual teamwork

\begin{tabular}{|l|c|c|c|}
\hline 3. In what extent do you identify with each of these issues? & Average & Standard Deviation & N \\
\hline Usually I feel motivated when I am performing a task. & 4,25 & 0,601 & 105 \\
\hline I feel free to express my opinion. & 4,21 & 0,805 & 105 \\
\hline A team must complete the work within the deadline. & 4,65 & 0,519 & 105 \\
\hline It is important a team to have diversified knowledges. & 4,74 & 0,501 & 105 \\
\hline A team must solve their problems. & 4,49 & 0,539 & 105 \\
\hline It is easier achieve certain goals working in team than individually. & 4,14 & 0,871 & 105 \\
\hline Working in virtual team promotes creativity. & 3,46 & 0,899 & 105 \\
\hline Team members should encourage each other. & 4,55 & 0,519 & 105 \\
\hline The discussion of ideas is important. & 4,75 & 0,476 & 105 \\
\hline Shouldn't be delays in replies to emails. & 4,50 & 0,606 & 105 \\
\hline It's important to have regular communication. & 4,64 & 0,521 & 105 \\
\hline Each element should participate in the tasks related to work. & 4,54 & 0,694 & 105 \\
\hline
\end{tabular}




\begin{tabular}{|l|l|l|l|}
\hline I prefer to work face-to-face with my colleagues than in virtual context. & 3,58 & 1,017 & 105 \\
\hline I like that my team has good ideas. & 4,66 & 0,534 & 105 \\
\hline Communication among members should be effective. & 4,70 & 0,458 & 105 \\
\hline I like to work with virtual tools. & 4,01 & 0,740 & 105 \\
\hline I usually work in team. & 4,10 & 0,796 & 105 \\
\hline It is more viable achieve the proposed goals when we work in virtual environments. & 3,23 & 0,775 & 105 \\
\hline Virtual environments provide me more confidence to do a work. & 3,06 & 0,853 & 105 \\
\hline I believe that virtual tools help in work development of a group. & 3,91 & 0,774 & 105 \\
\hline I trust more in my abilities. & 3,54 & 0,920 & 105 \\
\hline The virtual media facilitate the resolution of a problem. & 3,61 & 0,838 & 105 \\
\hline Working online helps me feel motivated. & 3,03 & 0,871 & 105 \\
\hline
\end{tabular}

We also verified that most participants consider the discussion of ideas as important, showing that a team must be creative and have good ideas. Creativity allows a team to be more flexible and effective solving problems, but development of trust is also important to perform a good work. Nevertheless, for participants, the collaboration tools don't have a significant influence in creativity and confidence.

On the other hand, the diversity of knowledges is an asset, thus the interaction among members with different skills and knowledges, in a virtual context, is considered to enrich the teamwork. The Motivation may have influence in productivity and creativity, but for participants working online may have not a significant influence in their personal motivation (Avg=3,03). However, the majority of participants likes to work with virtual tools (Avg=4,01).

Communication is needed mainly to keep a team cohesive, creating or reinforcing bond, which allow to mantain synergies among members. In this sense, for participants, communication may be regular and effective (cf. Table 3). The results also show us that personal contact, e-mail, telephone contact and file sharing applications are considered the most important tools to maintain a good communication among members (cf. Table 4).

Table 4 - Communication in virtual teamwork

\begin{tabular}{|l|c|c|c|}
\hline $\begin{array}{l}\text { 6. To what extent each of the important tools in communication } \\
\text { between the elements of a group? }\end{array}$ & Average & $\begin{array}{c}\text { Standard } \\
\text { Deviation }\end{array}$ & N \\
\hline Videoconference (ex: Skype, GoToMeeting) & 3,97 & 1,156 & 105 \\
\hline Audioconference (ex: Skype, ZOHO Meeting) & 3,80 & 1,220 & 105 \\
\hline Telephone Contact & 4,30 & 0,865 & 105 \\
\hline Personal Contact (Cara-a-Cara) & 4,79 & 0,494 & 105 \\
\hline E-mail & 4,47 & 0,785 & 105 \\
\hline File Sharing Applications (ex: Dropbox, WeTransfer) & 4,03 & 1,051 & 105 \\
\hline Shared Presentations (ex: Slideshare, Prezi) & 3,23 & 1,325 & 105 \\
\hline Instant Messages (ex: Hangout, Lync Online) & 3,33 & 1,246 & 105 \\
\hline CMS (ex: Joomla, Drupal) & 2,66 & 1,134 & 105 \\
\hline Social Networks (ex: Facebook, Twitter) & 3,44 & 1,315 & 105 \\
\hline Blogs (ex: Wordpress, Blogger) & 2,58 & 1,254 & 105 \\
\hline Shared Documents (ex: Google Drive, Microsoft Web Apps) & 3,41 & 1,253 & 105 \\
\hline Management Projects (ex: Microsoft Project, Projectlibre) & 2,84 & 1,294 & 105 \\
\hline
\end{tabular}

\section{Discussion and Conclusion}

In the last years we were faced with numerous transformations at technological level. In fact, distance between countries, organizations and people, which in a recent past prevented us to communicate, with each others, in a quick and easy way, was shortened by the current large number of advanced and diversified technologies... just at the distance of a click, or a simple touch. If in past it was almost impossible edit a document during the same temporal period and in teams composed by dispersed members, today this concern was minimized, or just disappeared. Now our biggest concern is to be focused in what we need to give boost to the economy: produce, create and innovate.

The use of tools for online collaboration is increasingly common in teams that want to communicate and work remotely. This tools approach members separated by 'a wall or an ocean', allowing them to interact and communicate with each other, accessing a wide range of knowledge and information, as well as enabling the contact with colleagues with multiple specializations and cultures. 
Tools for online collaboration may include videoconference, audioconference, instant messages, e-mail, file sharing, projects management and many other features. However tools with asynchronous characteristics (e.g., e-mail, file sharing applications) are considered less rich in creating relational bonds, which may affect negatively the information sharing (e.g., delays, misunderstandings, conflits).

To perceive if collaboration in virtual context may improve a team's performance and contribute for their creative process, we analysed, through SPSS software, the frequency with which participants use these tools and how they perceive them as adequate to work, communicate and improve productivity (and enhance creativity).

To verify how often participants use these tools and how they perceive them as important in communication we perform a descriptive analysis. Additionally to collect data related with the influence of these tools on productivity and creativity we also perform a principal component analysis.

Most participants prefer to interact and communicate face-to-face in teamwork and through e-mail in individual work. Personal contact (face-to-face) is also considered determinant to enhance creativity.

We found out that in teamwork is easier to achieve goals than individually. Influence of collaboration tools in confidence and motivation was not considered to be significative between team members.

We also verified that a team must have good ideas and members must discuss them among each other. The majority of participants like to work with tools online and think that communication must be regular and effective, avoiding delays on reply on e-mails.

The results allow us to respond to the objective proposed, and may contribute to a theoretical and organizational context. In theoretical context this study contributes to comprise the importance of using collaboration tools in work development and communication among users of these tools (working as team members), and how they view these tools, when they work and communicate; and also if these tools may improve teamwork productivity.

To the organizational context this study contributes to improve online teamwork and shows some errors that must be avoided within team's communication. Even with some limitations this research may contribute to comprise the challenges and assets provided by these online technologies when are used and adapted in different communication stages of teamwork. We hope this project may enhance the development of new studies to improve teamwork, productivity and communication in virtual context.

Anyway, nowadays, technologies are essential, and we should not forget that we may have many facilities and different ways to communicate and work through a virtual world, but talking, face-to-face, continues to be a good option, when possible.

\section{References}

Amabile, T. M. (1998). How to kill creativity. Harvard Business Review, 76(5), 76-87. Accessed ｏn May 7, 2015, from http://gwmoon.knu.ac.kr/Lecture_Library_Upload/HOW_TO_KILL_CREATIVITY.pdf

Anderson, A .H., Mcewan, R., Bal, J. \& Carletta, J. (2007). Virtual team meetings: An analysis of communication and context. In Ebrahim, N. A., Ahmed, S. \& Taha, Z. (2009). Virtual teams: literature review. Australian Journal of Basic and Applied Sciences, 3(3), 2653-2669.

Back, K. W. (1951). Influence through social communication. In Driskell, J. E., Radtke, P. H. \& Salas, E. (2003). Virtual teams: effects of technological mediation on team performance. Group Dynamics: Theory, Research, and Practice, 7(4), 297-323.

Bolstad, C. A. \& Endsley, M. R. (2003). Tools for supporting team collaboration. Proceedings of the Human Factors and Ergonomics Society Annual Meeting, 47(3), 374-378.

Cascio, W. F. (2000). Managing a virtual workspace. The Academy of Management Executive, 14(3), 81-90.

Cramton, C. D. (2001). The mutual knowledge problem and its consequences for dispersed collaboration. Organization Science, 12(3), 346-371.

Cummings, J. (2004). Work groups, structural diversity, and knowledge sharing in a global organization. Management Science, 50(3), $352-364$

Curtis, R. C., \& Miller, K. (1986). Believing another likes or dislikes you: Behaviors making the beliefs come true. In Driskell, J. E., Radtke, P. H. \& Salas, E. (2003), Virtual teams: effects of technological mediation on team performance. Group Dynamics: Theory, Research, and Practice, 7(4), 297-323.

Driskell, J. E., Radtke, P. H. \& Salas, E. (2003). Virtual teams: effects of technological mediation on team performance. Group Dynamics: Theory, Research, and Practice, 7(4), 297-323.

Firestien, R. L. (1996). Leading on the creative edge. In Godar, S. \& Ferris, S. P. (2004). A virtual and collaborative teams: process, technologies, and practice (1st ed.). London: Idea Group Publishing.

Friedman, R. A. \& Currall, C. C. (2003). Conflict escalation: dispute exacerbating elements of e-mail communication. Human Relations, 56(11), 1325-1347.

Gera, S. (2013). Virtual teams versus face to face teams: a review of literature. Journal of Business and Management, 11(2), 1-4. 
Godar, S. \& Ferris, S. P. (2004). A virtual and collaborative teams: process, technologies, and practice (1st ed.). London: Idea Group Publishing.

Herbsleb, J. D., Mockus, A., Finholt, T. A. \& Grinter, R. E. (2000). Distance, dependencies, and delay in a global collaboration. In Proceedings, ACM Conference on Computer-Supported Cooperative Work, 2(7), 319-328.

Hogan, J. \& Salas, E. (1987) - Virtual teams: effects of technological mediation on team performance. Group Dynamics: Theory, Research, and Practice, 7(4), 297-323.

Lomas, C., Burke, M. \& Page, C. L. (2008). Collaboration tools. ELI Papers and reports, EDUCAUSE Learning Initiative. Accessed on October 8, 2014, from https://net.educause.edu/ir/library/pdf/ELI3020.pdf

Lott, A. J., \& Lott, B. E. (1961). Group cohesiveness, communication level, and conformity. In Driskell, J. E., Radtke, P. H. \& Salas, E. (2003). Virtual teams: effects of technological mediation on team performance. Group Dynamics: Theory, Research, and Practice, 7(4), 297-323

Nemiro, J., Beyerlein, M., Bradley, L. \& Beyerlein, S. (2008). The handbook of high-performance virtual teams: a toolkit for collaborating across boundaries (1st ed.). San Francisco, CA: Jossey-Bass.

Olson, J., Teasley S., Covi L. \& Olson G (2002). The (currently) unique advantages of collocated work. In Lu, M., Watson-Manheim, M. B., Chudoba, K. M. \& Wynn, E. (2006). Virtuality and team performance: understanding the impact of variety of practices. Journal of Global Information Technology Management, 9(1), 4-23.

Richards, R. (1999). Four Ps of creativity. In Godar, S. \& Ferris, S. P. (2004). A virtual and collaborative teams: process, technologies, and practice (1st ed.). London: Idea Group Publishing.

Roffe, I. (1999). Innovation and creativity in organisations: a review of the implications for training and development. Journal of European Industrial Training, 23(4/5), 224-241.

Schmidt, J. B., Montoya-Weiss, M. M., Massey, A. P. (2001). New product development decision-making effectiveness: comparing individuals, face-to-face teams, and virtual teams. Decision Sciences, 32(4), 575-600.

Stewart, G. L. \& Barrick, M. R. (2000). Team structure and performance: assessing the mediating role of instrateam process and the moderating role of task type. Academy of Management Journal, 43(2), 135-148.

Warkentin, M. E., Sayeed, L. \& Hightower, R. (1997). Virtual teams versus face-to-face teams: na exploratory study of a web-based conference system. Decision Sciences, 32(4), 575-600.

Watson-Manheim, M. B. \& Belanger, F. (2002). Exploring communication-based work processes in virtual work environments. In Proceedings of the $35^{\text {th }}$ Hawaii International Conference on System Sciences.

Wong, S. \& Burton, R. M. (2000). Virtual teams: what are their characteristics, and impact on team performance? Computational \& Mathematical Organization Theory, 6(4), 339-360.

Xu, J., Zhang, J., Harvey, T. \& Young, J. (2008). A survey of asynchronous collaboration tools. Information Technology Journal, 7(8), 1182-1187. 